\title{
Evaluation of swallowing in patients with hereditary spastic paraplegias
}

\author{
Avaliação da deglutição em pacientes com paraplegias espásticas hereditárias \\ Antonio ORLACCHIO',2
}

${ }^{1}$ Istituto di Ricovero e Cura a Carattere Scientifico (IRCCS) Fondazione Santa Lucia, Centro Europeo di Ricerca sul Cervello (CERC), Laboratorio di Neurogenetica, Rome, Italy;

${ }^{2}$ Università di Perugia, Dipartimento di Scienze Chirurgiche e

Biomediche, Perugia, Italy.

Correspondence:

Antonio Orlacchio;

Laboratorio di Neurogenetica,

Centro Europeo di Ricerca sul

Cervello (CERC), Istituto di

Ricovero e Cura a Carattere

Scientifico (IRCCS) Fondazione

Santa Lucia, 64 Via del Fosso di

Fiorano, 00143 Rome, Italy; E-mail:

a.orlacchio@hsantalucia.it

(D) http://orcid.org/0000-0002-2602-3281

Conflict of interest:

There is no conflict of interest to

declare.

Received 29 September 2019;

Accepted 07 October 2019.

(cc) BY
I $\mathrm{n}$ this two-center, exploratory, cross-sectional, prevalence study conducted at two teaching hospitals in the Brazilian cities of Porto Alegre and Campinas, Laís Alves Jacinto-Scudeiro and colleagues appraised the frequency and clinical characterization of dysphagia in different types of hereditary spastic paraplegias (HSPs). The article is educational, since swallowing dysfunction is weakly studied in HSP and its existence can lead to important respiratory and nutritional complications.

The literature on this matter is not only exiguous, but fragmented and not entirely matured either ${ }^{1,2,3}$. In September 2019, the term "dysphagia and hereditary spastic paraplegia" was identified only in 16 articles in the PubMed database. Also, the term "swallowing dysfunction and hereditary spastic paraplegia" was found only in one article in the PubMed database. This may suggest that neurologists are not familiar with swallowing dysfunction in hereditary spastic paraplegias.

In this issue of Arquivos de Neuropsiquiatria, Jacinto-Scudeiro et al. ${ }^{4}$ analyzed affected individuals with pure and complicated forms of HSP and they detected that clinically significant oropharyngeal dysphagia was only present in complicated forms of the disease. Specifically, SPG11 and CTX presented highest risks for dysphagia, indicating that surveillance of swallowing function should be part of the management of patients with these disorders. On the other hand, data concerning the lack of clinically perceptible changes in swallowing even in advanced stages of pure forms of HSP are significant for the differential diagnosis with other neurodegenerative conditions that mainly affect the corticospinal tract such as primary lateral sclerosis, in which dysphagia is frequent and may be an early symptom.

The content of this manuscript is of high clinical and scientific importance. The dysphagia scales of this report are well-validated and widely used instruments that are easy to execute with low related costs ${ }^{5,6,7,8,9}$, being suitable outcomes to answer the study question on the clinical characterization of oropharyngeal dysphagia in patients with HSP. Moreover, the authors are experienced researchers in the field. The only weakness of the study was the lack of an objective evaluation of swallowing, which prevented the authors from evaluating the presence of silent or subclinical aspirations.

Within the problematic valuation and serious management of a relevant disabling syndrome such as HSP, data made available by this article draw attention to significant but often unnoticed prospects in the field of neurodegenerative diseases, starting with the appreciation that this is an active and stimulating subspecialty in which precise researches and interventions will probably reveal hypothetically treatable conditions. 
1. Lo Giudice T, Lombardi F, Santorelli FM, Kawarai T, Orlacchio A. Hereditary spastic paraplegia: clinical-genetic characteristics and evolving molecular mechanisms. Exp Neurol. 2014 Nov;261:518-39. https://doi.org/10.1016/j.expneurol.2014.06.011

2. Coutinho P, Barros J, Zemmouri R, Guimarães J, Alves C, Chorão $R$, et al. Clinical heterogeneity of autosomal recessive spastic paraplegias: analysis of 106 patients in 46 families. Arch Neurol. 1999 Aug;56(8):943-9. https://doi.org/10.1001/archneur.56.8.943

3. Bot ST, Burggraaff RC, Herkert JC, Schelhaas HJ, Post B, Diekstra $A$, et al. Rapidly deteriorating course in Dutch hereditary spastic paraplegia type 11 patients. Eur J Hum Genet. 2013 Nov;21(11):1312-5. https://doi.org/10.1038/ejhg.2013.27

4. Jacinto-Scudeiro LA, Dariva Machado G, Ayres A, et al. Prevalence of oropharyngeal dysphagia in hereditary spastic paraplegias. Arq Neuropsiquiatr. 2019;77(12):83-7. https://doi.org/10.1590/0004-282X20190180

5. Magalhães Junior HV, Pernambuco LA, Souza LB, Ferreira MA, Lima KC. Translation and cross-cultural adaptation of the Northwestern Dysphagia Patient Check Sheet to Brazilian Portuguese. CoDAS. 2013;25(4):369-74. https://doi.org/10.1590/S2317-17822013000400012

6. Padovani AR, Moraes DP, Mangilli LD, Andrade CRF. Protocolo de Avaliação do Risco para a Disfagia (PARD). In: Andrade CRF, Limongi SCO (Org). Disfagia: prática baseada em evidências. São Paulo: Sarvier; 2012. p. 62-73.

7. Crary MA, Mann GD, Groher ME. Initial psychometric assessment of a functional oral intake scale for dysphagia in stroke patients. Arch Phys Med Rehabil. 2005 Aug;86(8):1516-20. https://doi.org/10.1016/j.apmr.2004.11.049

8. Ayres A, Ghisi M, Rieder CR, Manor Y, Olchik MR. Translation and cultural adaptation of Swallowing Disturbance questionnaire for Brazilian Population. CEFAC. 2016;18(4):828-34. https://doi.org/10.1590/1982-021620161844016

9. Gonçalves MI, Remaili CB, Behlau M. Cross-cultural adaptation of the Brazilian version of the Eating Assessment Tool - EAT-10. CoDAS. 2013;25(6):601-4. https://doi.org/10.1590/S2317-17822013.05000012 